\title{
Folic Acid-Targeted Paclitaxel-Polymer Conjugates Exert Selective Cytotoxicity and Modulate Invasiveness of Colon Cancer Cells
}

\author{
Antonella Grigoletto (D), Gabriele Martinez, Daniela Gabbia (D), Tommaso Tedeschini, Michela Scaffidi, \\ Sara De Martin * (D) and Gianfranco Pasut*(D)
}

\begin{abstract}
Pharmaceutical and Pharmacological Sciences Department, University of Padua, Via F. Marzolo 5, 35131 Padova, Italy; antonella.grigoletto@unipd.it (A.G.); gabriele.martinez8740@gmail.com (G.M.); daniela.gabbia@unipd.it (D.G.); tommaso.tedeschini@unipd.it (T.T.); michela.scaffidi@unipd.it (M.S.)

* Correspondence: sara.demartin@unipd.it (S.D.M.); gianfranco.pasut@unipd.it (G.P.); Tel.: +39-049-827-5077 (S.D.M.); +39-049-8275-694 (G.P.)
\end{abstract}

Citation: Grigoletto, A.; Martinez, G.; Gabbia, D.; Tedeschini, T.; Scaffidi, M.; Martin, S.D.; Pasut, G. Folic

Acid-Targeted Paclitaxel-Polymer

Conjugates Exert Selective

Cytotoxicity and Modulate Invasiveness of Colon Cancer Cells. Pharmaceutics 2021, 13, 929. https:// doi.org/10.3390/pharmaceutics13070929

Academic Editor: Tomáš Etrych

Received: 9 June 2021

Accepted: 18 June 2021

Published: 23 June 2021

Publisher's Note: MDPI stays neutral with regard to jurisdictional claims in published maps and institutional affiliations.

\begin{abstract}
Although selective tumor delivery of anticancer drugs has been sought by exploiting either passive targeting or by ligand-mediated targeting, a selective anticancer therapy remains an unmet medical need. Despite the advances which have been achieved by nanomedicines, nanosystems such as polymer-drug conjugates still miss the goal of clinical efficacy. In this study, we demonstrated that polymer-drug conjugates require a thoroughly chemical design and the right targeting agent/polymer ratio to be selective and effective towards cancer cells. In particular, two PEG conjugates carrying paclitaxel and targeted with different folic acid (FA)/PEG ratios (one or three) were investigated. The cytotoxicity study in positive (HT-29) and negative (HCT-15) FA receptor (FR)-cell lines demonstrated that the conjugates with one or three FAs were 4- or 28-fold more active in HT-29 cells, respectively. The higher activity of the 3-FA conjugate was confirmed by its strong impact on cell cycle arrest. Furthermore, FA targeting had a clear effect on migration and invasiveness of HT-29 cells, which were significantly reduced by both conjugates. Interestingly, the 3-FA conjugate showed also an improved pharmacokinetic profile in mice. The results of this study indicate that thorough investigations are needed to optimize and tune drug delivery and achieve the desired selectivity and activity towards cancer cells.
\end{abstract}

Keywords: drug delivery; polymer conjugates; anticancer therapy; active targeting; paclitaxel; PEGylation

\section{Introduction}

A variety of cytotoxic drugs have long been used in cancer chemotherapy, in single or combined protocols, with the aim of hitting and killing tumor cells while sparing healthy cells. Tumor selectivity with most of these drugs has been sought through preferential cytotoxicity against cells with higher proliferation or metabolic rates. However, these conditions are typical features of tumor cells but also many healthy cells, such as those of the bone marrow, digestive system epithelium and hair follicles. Furthermore, most existing anticancer drugs enter cells through non-specific lipophilic interactions with the cell membrane. Therefore, the therapeutic index of anticancer drugs is usually very low, since remarkable toxic side effects might compromise the therapeutic outcome.

The selective delivery of cytotoxic drugs to tumor cells have been extensively studied in an attempt to accumulate the payload preferentially in tumor tissues by exploiting the conjugation of targeting agents directly to these drugs or to the delivery systems carrying the drugs. This approach of ligand-mediated targeting is intended for improving the internalization of targeted nanomedicines by cells overexpressing a specific receptor. At the same time, it is important to increase the fraction of an administered nanomedicine that reaches the target site by exploiting the enhanced permeability and retention (EPR) 
effect, a feature typical of solid cancers [1]. Although both ligand-mediated targeting and the EPR effect have shown controversial results, which have not yet fulfilled the promise of a selective cancer therapy, their exploitation must be pursued and developed to reduce the toxic side effects of chemotherapies [2]. Antibody drug conjugates (ADCs) can be cited as an example of a targeted nanomedicine that can exploit both targeting approaches with great therapeutic outcomes [3]. Nevertheless, for ADCs the progress from the bench to the clinic is not easy [4] and the cost of such drugs might represent a limitation.

Polymer-drug conjugates have been studied by several researchers who obtained interesting results that unfortunately have not yet been translated into a clinical approved derivative. Most of the advanced conjugates investigated in clinical trials were relying only on the EPR effect for cancer therapy but did not achieve the desired selective cytotoxicity. During the years, researchers have learned about the limitations of the first conjugates, such as the difficulties of batch-to-batch reproducibility and the inadequacy or absence of proper ligand-mediated targeting. Still, such a drug delivery system offers unique properties, such as good water solubility of hydrophobic drugs, high drug payload and tunable physicochemical features.

To further investigate the potential of this delivery approach, the synthesis of macromolecular prodrugs is presented here. Poly(ethylene glycol) (PEG) was chosen as a polymeric carrier owing to its known biocompatibility, stability and solubility [5]. Heterobifuctional PEGs, eventually modified with a dendron structure, have the advantage to be suited for a defined structure design of the conjugates in which the targeting moiety is spatially separated from the drug moiety, thus generating a homogeneous structure that can overcome some limitations of random conjugates, as we have shown in other studies [6-9]. To further increase the selectivity of these PEG conjugates, the role of an active targeting agent was also investigated by linking folic acid (FA) to a heterobifunctional PEG. Paclitaxel (PTX) was used as the model drug.

The FA receptor is overexpressed in several types of human cancers, especially ovarian, but also kidney, uterus, brain, colon and lung cancer [10]. The folate receptor (FR) participates in the cellular accumulation of folate through the process of potocytosis, and is present as three different isoforms, i.e., two glycosylphosphatidylinositol-anchored membrane proteins, FR- $\alpha$ and FR- $\beta$, and a soluble form called FR- $\gamma$ [11,12]. However, these receptors are expressed in the choroid plexus and placenta, and not in other healthy tissues, except for the lung, thyroid and kidney, where their expression is low. From a functional point of view, the $\alpha$ isoform of FR (FR $\alpha$ ) has been linked to proliferation, migration, and invasion of tumor cells [13], and its overexpression has been demonstrated in approximately $40 \%$ of human colorectal carcinomas [14] and is associated with a worse prognosis [15]. Interestingly, FR $\alpha$ expression was also demonstrated in a subset of colorectal cancer liver metastases and has been independently associated with early death after hepatic resection [16], thereby confirming the peculiar role of this receptor not only in primary tumors but also in the metastasis process.

In light of these considerations and taking into account that FR $\alpha$ has been pointed to as a promising target for colon cancer-targeted therapy, we studied two PTX-PEG conjugates targeted with different amounts of FA and compared them with non-targeted conjugates. We could identify a lead conjugate characterized by a promising cytotoxic and antimetastatic activity in vitro and an improved pharmacokinetic profile in mice.

\section{Materials and Methods}

\subsection{Materials}

PTX was from LC Laboratories (Woburn, MA, USA). Boc-NH-PEG-NHS (5 kDa) and MeO-PEG- $\mathrm{NH}_{2}(5 \mathrm{kDa})$ were obtained from Iris Biotech $\mathrm{GmbH}$ (Marktredwitz, Germany). Folic acid (FA), N-Boc-1,5-diaminopentane, $N, N$-dicyclohexylcarbodiimmide (DCC), NHydroxysuccinimide (NHS), ethyl-3-(3-(dimethylamino)propyl)carbodiimide (EDC), 1hydroxybenzotriazole (HOBT), succinic anhydride, silica gel $\left(\mathrm{SiO}_{2}\right)$, trifluoroacetic acid (TFA), triethylamine $\left(\mathrm{Et}_{3} \mathrm{~N}\right)$, 2,4,6-trinitrobenzenesulfonic acid (TNBS), dimethylsulfoxide- 
$\mathrm{d}_{6}$, methanol- $\mathrm{d}_{4}$, chloroform- $\mathrm{d}$ and all other chemical reagents including salts and solvents were purchased from Merk (Darmstadt, Germany).

\subsection{Methods}

Analytical RP-HPLC: analytical reverse phase (RP) HPLC was performed on an Agilent 1200 Series HPLC with online UV detection from Agilent Technologies (Santa Clara, CA, USA), using a Jupiter C18 column $(4.6 \times 250 \mathrm{~mm} ; 5 \mu \mathrm{m}$; Phenomenex, Castel Maggiore, Italy) operating at a flow rate of $1 \mathrm{~mL} / \mathrm{min}$. Elution experiments were conducted with $\mathrm{H} 2 \mathrm{O}+0.05 \%$ TFA (eluent A) and ACN $+0.05 \%$ TFA (eluent B) (gradient B\%: 0 min $5 \%, 25 \min 40 \%, 30 \min 70 \%, 35 \min 95 \%, 40 \min 5 \%$ B).

Mass spectrometry analysis: mass spectrometry-based analyses of FA derivatives and SPTX were performed with a mass spectrometer Xevo G2-S Q-Tof (Waters, Milford, MA, USA) equipped with an electrospray source. Samples were analyzed in MS positive ion mode. Measurements were conducted at a capillary voltage of $3 \mathrm{kV}$ and at cone and extractor voltages of 35 and $1 \mathrm{~V}$, respectively. Instrument control and data acquisition and processing were achieved with Masslynx software (version 4.1, Micromass, Santa Clara, CA, USA).

Mass spectra of PEG-FA were obtained using a REFLEX time-of-flight instrument (4800 Plus MALDI TOF/TOF, AB Sciex, Framingham, MA, USA) equipped with a SCOUT ion source, operating in the positive linear mode. A pulsed UV laser beam (nitrogen laser, $\lambda 337 \mathrm{~nm}$ ) generated ions that were accelerated to $25 \mathrm{kV}$. The matrix, a saturated solution of sinapinic acid in water/ACN $(1: 1, v / v)+0.1 \%$ TFA $(v / v)$, was mixed with an equal volume of sample solution and $1-2 \mu \mathrm{L}$ were loaded on the plate.

NMR analysis: all ${ }^{1} \mathrm{H}-\mathrm{NMR}$ spectra were recorded on a Bruker $400 \mathrm{MHz}$ spectrometer (Bruker, Billerica, MA, USA) with TMS as the internal standard.

\subsection{Synthesis of PTX-PEG, PTX-PEG-FA and PTX-PEG-(FA) ${ }_{3}$ Conjugates}

Preparation of FA-DAP-NH $\mathrm{NH}_{2}: 1 \mathrm{~g}$ of FA $(2.26 \mathrm{mmol})$ was solubilized at $40{ }^{\circ} \mathrm{C}$ in anhydrous DMSO. Next, $234 \mathrm{mg}$ of DCC ( $0.5 \mathrm{eq}, 1.13 \mathrm{mmol})$ was added and, after $30 \mathrm{~min}$, $943 \mu \mathrm{L}$ of $\mathrm{N}$-Boc-1,5-diaminopentane (2 eq, $4.53 \mathrm{mmol}, \mathrm{d}=0.972 \mathrm{~g} / \mathrm{mL}$ ) was added to the solution and the reaction was stirred at room temperature for $24 \mathrm{~h}$. The reaction was monitored by RP-HPLC using the conditions reported above and the UV detector (Agilent Technologies, Santa Clara, CA, USA) settled at $280 \mathrm{~nm}$. The mixture was filtered and added dropwise into a diethyl ether/THF 1:1 $(v / v)$ solution. The precipitate was recovered by filtration, washed with a diethyl ether/THF 1:1 $(v / v)$ mixture and dried under vacuum (yield: $1.2 \mathrm{~g}, 86.3 \% w / w$ ). The product was characterized by ESI-TOF mass spectrometry (Waters, Milford, MA, USA). ESI-MS [ $m / z$ ]: $626.29(\mathrm{M}+\mathrm{H})^{+}$[Theorical mass: 625.29 Da].

Next, $1.2 \mathrm{~g}$ of Boc-DAP-FA $(1.92 \mathrm{mmol})$ was dissolved in $25 \mathrm{~mL}$ of DMSO/CF $3 \mathrm{COOH}$ $1: 2(v / v)$ mixture for $2 \mathrm{~h}$ to remove the protecting group t-Boc. After monitoring the reaction by RP-HPLC, as reported above, the mixture was evaporated to remove TFA and the obtained oil was dropped into a diethyl ether/THF 1:1 $(v / v)$ mixture. The product was recovered by filtration, washed with a diethyl ether/THF 1:1 $(v / v)$ mixture and dried under vacuum (yield: $1 \mathrm{~g}, 98.25 \% \mathrm{w} / \mathrm{w}$ ). The intermediate FA-DAP- $\mathrm{NH}_{2}$ was characterized through ESI-TOF mass spectrometry. ESI-MS $[m / z]$ : $526.28(\mathrm{M}+\mathrm{H})^{+}[$Theorical mass: 525.24 Da].

Preparation of $\mathrm{H}_{2} \mathrm{~N}-\mathrm{PEG}-\mathrm{FA}$ and $\mathrm{H}_{2} \mathrm{~N}-\mathrm{PEG}-(\mathrm{FA})_{3}$ : the intermediates Boc-NH-PEG-FA and Boc-NH-PEG-(FA) $)_{3}$ were synthesized and purified using the same procedure. Here we report the procedure for Boc-NH-PEG-(FA) ${ }_{3}$ as an example. The dendron structure Boc-NH-PEG-(NHS) $)_{5}$ was prepared as described elsewhere $[17,18]$. Briefly, to $1 \mathrm{~g}$ of FADAP- $\mathrm{NH}_{2}$ (12 eq, $1.9 \mathrm{mmol}$ ) previously solubilized in $6 \mathrm{~mL}$ of DMSO at $40{ }^{\circ} \mathrm{C}, 48 \mu \mathrm{L}_{\text {of }} \mathrm{Et}_{3} \mathrm{~N}$ $(0.34 \mathrm{mmol})$ and $600 \mathrm{mg}$ of Boc-NH-PEG-(NHS) $(0.11 \mathrm{mmol})$ were added. The mixture was left to react for $24 \mathrm{~h}$ at room temperature. The intermediate was purified by chromatography on a $\mathrm{SiO}_{2}$ column $(30 \times 2.5 \mathrm{~cm})$ eluted with a chloroform/ethanol/acetone/ammonia mixture (2:2:0.5:0.25 to 2:2:1:0.5) and determined by RP-HPLC using the same conditions 
reported above with the UV detector settled at $280 \mathrm{~nm}$. The purified product was concentrated under vacuum, solubilized in $1 \mathrm{~mL}$ of $\mathrm{CH}_{2} \mathrm{Cl}_{2}$ and dropped in cold diethyl ether. The precipitate was left for $1 \mathrm{~h}$ at $-20{ }^{\circ} \mathrm{C}$, recovered by centrifugation and dried under vacuum (yield: $293 \mathrm{mg}, 38 \% w / w$ ). The modification with FA was verified by ${ }^{1} \mathrm{H}-\mathrm{NMR}$ and MALDI-TOF.

Following this, $290 \mathrm{mg}$ of Boc-NH-PEG-(FA) 3 was dissolved in a $\mathrm{CH}_{2} \mathrm{Cl}_{2} / \mathrm{CF}_{3} \mathrm{COOH} /$ $\mathrm{H}_{2} \mathrm{O}$ (54:45:1) mixture for $3 \mathrm{~h}$ to remove the protecting group $\mathrm{t}$-Boc. The solution was evaporated to remove the TFA and the obtained oil was solubilized in $\mathrm{CH}_{2} \mathrm{Cl}_{2}$ and dropped in cold diethyl ether. The product was recovered by centrifugation, dried under vacuum (yield: $276 \mathrm{mg}, 95 \% \mathrm{w} / \mathrm{w}$ ) and characterized through ${ }^{1} \mathrm{H}-\mathrm{NMR}$.

Synthesis of 2'-succinyl-paclitaxel (SPTX): $293 \mathrm{mg}$ (5 eq, $2.93 \mathrm{mmol}$ ) of succinic anhydride was added to $500 \mathrm{mg}(0.59 \mathrm{mmol})$ of PTX, dissolved in $15 \mathrm{~mL}$ of anhydrous pyridine. The reaction was stirred at room temperature for $48 \mathrm{~h}$. The SPTX was purified by chromatography on a $\mathrm{SiO} 2$ column $(30 \times 2.5 \mathrm{~cm})$ eluted with a chloroform $/ \mathrm{methanol}$ mixture (97:3 to 90:10) and determined by thin-layer chromatography (TLC; Rf 0.5 in chloroform/methanol, 90:10). The product yield was 97\% $(w / w)$. SPTX was characterized through ESI-TOF mass spectrometry and ${ }^{1} \mathrm{H}-\mathrm{NMR}$. ESI-MS [m/z]: $954.46(\mathrm{M}+\mathrm{H})^{+}$ [Theorical mass: $953.35 \mathrm{Da}] .{ }^{1} \mathrm{H}-\mathrm{NMR}:\left(\mathrm{CD}_{3} \mathrm{OD}, \delta \mathrm{ppm}\right), 1.15$ (s, 3H, C16), $1.24(\mathrm{~s}, 3 \mathrm{H}$, C17), 1.68 (s, 3H, C18), 1.79 (s, 3H, C19), 2.24 (s, 3H, C31), 2.38 (s, 3H, C29), 2.5-2.7 (m, $4 \mathrm{H},-\mathrm{CH}_{2}-\mathrm{CH}_{2}$-succinic spacer), 4.9 (d, 1H, C5), 5.66 (d, 1H, C2' ), 6.27 (s, 1H, C10), 7.25 (s, $\left.3^{\prime}-\mathrm{Ph}\right), 7.4$ (m, 3'-NBz), 7.5 (m, 2-OBz), 7.75 (d, 3’ NBz), 8.1 (d, 2-OBz).

Synthesis of PTX-PEG, PTX-PEG-FA and PTX-PEG-(FA) $)_{3}$ conjugates: the conjugates were synthesized and purified using the same procedure. The preparation of PTX-PEG$(\mathrm{FA})_{3}$ is here described as an example. To $61.8 \mathrm{mg}$ of SPTX (2 eq, $\left.0.065 \mathrm{mmol}\right)$ dissolved in anhydrous DMF, $13.7 \mathrm{mg}$ (1.1 eq, $0.071 \mathrm{mmol}$ ) of EDC and $13.1 \mathrm{mg}$ (1.5 eq, $0.097 \mathrm{mmol})$ of HOBT, previously dissolved in anhydrous DMF, were added. After $5 \mathrm{~h}$ under stirring at room temperature, $\mathrm{H}_{2} \mathrm{~N}-\mathrm{PEG}-(\mathrm{FA})_{3}(220 \mathrm{mg})$, previously dissolved in DMF, was added (PEG/SPTX ratio 1:2) and let to react for $48 \mathrm{~h}$. Then DMF was removed under vacuum and the residue was dissolved in an ammonium acetate buffer of $10 \mathrm{mM}, \mathrm{pH}$ 4.7. The excess of SPTX was eliminated by extractions with diethyl ether and the solution was dialyzed against ammonium acetate buffer $10 \mathrm{mM}$, pH 4.7 before lyophilization. The product was characterized by ${ }^{1} \mathrm{H}-\mathrm{NMR}$ and RP-HPLC. The content of free PTX was evaluated by RPHPLC, preparing conjugates solutions at the concentration of $5 \mathrm{mg} / \mathrm{mL}$ in methanol. The RP-HPLC conditions were the same as reported above with the UV detector settled at $227 \mathrm{~nm}$.

\subsection{Determination of Conjugated PTX}

The content of the conjugated drug was evaluated by RP-HPLC after freeing PTX. The solutions of conjugates and PTX (for the calibration curve) were prepared in methanol and underwent the same treatment. Following the addition of $2 \%(v / v)$ of $0.2 \mathrm{~N} \mathrm{NaOH}$, the solutions were incubated at $50{ }^{\circ} \mathrm{C}$ for $2 \mathrm{~h}$. The drug was extracted by ethyl acetate and after evaporation of the organic phase, the residue was solubilized in methanol and analyzed in RP-HPLC, as reported above. The elution was performed using a Jupiter C18 column $\left(21.2 \times 250 \mathrm{~mm} ; 5 \mu \mathrm{m}\right.$; Phenomenex), eluted with $\mathrm{H}_{2} \mathrm{O}+0.05 \%$ TFA (eluent A) and $\mathrm{MeCN}+0.05 \%$ TFA (eluent B) at $1.0 \mathrm{~mL} / \mathrm{min}$ flow rate (gradient B\%: $0^{\prime} 5 \%, 25^{\prime} 40 \%, 30^{\prime}$ $\left.70 \%, 35^{\prime} 95 \%, 40^{\prime} 5 \% \mathrm{~B}\right)$. The UV detector was settled at $227 \mathrm{~nm}$. The amount of conjugated PTX was calculated using a calibration curve of drug solutions at known concentrations.

\subsection{Dynamic Light Scattering (DLS) Analysis}

The mean hydrodynamic diameter and the stability of polymeric structures of PTXPEG, PTX-PEG-FA and PTX-PEG-(FA) $)_{3}$ conjugates were analyzed using a light scattering instrument (Malvern Zetasizer Nano ZS, Malvern, UK). To evaluate the stability of the conjugates, solutions of each compound $(7 \mathrm{mg} / \mathrm{mL})$ were prepared in PBS at $\mathrm{pH} 7.4$ and 
the size of the micelles was monitored every $20 \mathrm{~min}$ for $6 \mathrm{~h}$ and at $24 \mathrm{~h}$. The instrument was settled at $37^{\circ} \mathrm{C}$.

\subsection{Cell Cultures}

The colorectal cancer cell lines HT-29 (FR-positive) and HCT-15 (FR-negative) were a kind gift from Professor Antonio Rosato (University of Padova, Padova, Italy). Cell were maintained at $37{ }^{\circ} \mathrm{C}$ in standard $\mathrm{CO}_{2}(5 \%)$ and humidity conditions, in the RPMI medium with the addition of 10\% foetal bovine serum (FBS), 1\% HEPES, 1\% glutamine, 1\% Penicillin Streptomycin (all purchased from Corning, Corning, NY, USA).

\subsection{Immunocytochemistry}

To assess the FR expression in HT-29 and HCT-15 cells, we performed an immunofluorescence analysis coupled to confocal microscopy [19]. Briefly, cells were seeded into glass coverslip-coated plates $(20,000$ cells $/ \mathrm{mL})$, fixed for $20 \mathrm{~min}$ with $4 \%$ PFA at room temperature and incubated for $10 \mathrm{~min}$ with $5 \%$ FBS to block unspecific cross-reaction. After the PBS wash, cells were incubated overnight at $4{ }^{\circ} \mathrm{C}$ with a primary antibody directed against the folate receptor (dilution 1:50, sc-515521 Santa Cruz), and then at $37^{\circ} \mathrm{C}$ for $1 \mathrm{~h}$ with an anti-mouse Alexa Fluor 568-conjugated secondary antibody (dilution 1:500). To counterstain cell nuclei, the reagent Hoechst 33342 was used (Thermo Scientific, Waltham, MA, USA). Cell images were acquired by means of a confocal microscope Zeiss LSM 800 (Zeiss, Milan, Italy) and analyzed with the ImageJ software (ver. 1.52, developed by NIH, Bethesda, MD, USA).

\subsection{Cell Viability Studies}

Cell viability was assessed by the ATPlite (Perkin-Elmer Inc., Waltham, MA, USA) kit, following the manufacturer's instructions. Briefly, HCT-15 and HT-29 cells were seeded (3000 cells/well) in a 96-well plate [19]. After $24 \mathrm{~h}$, cells were incubated for $48 \mathrm{~h}$ with increasing concentrations of PTX and PTX conjugates (range: $0.0125 \mathrm{pg} / \mathrm{mL}-50 \mathrm{mg} / \mathrm{mL}$, PTX equiv.). At the end of the incubation period, luminescence was measured by the multiplate reader Victor Nivo (Perkin-Elmer Inc., Waltham, MA, USA). The 50\% inhibitory concentrations $\left(\mathrm{IC}_{50}\right)$ were calculated by the appropriate nonlinear regression fit, using the GraphPad Prism software (San Diego, CA, USA), version 8.0.

\subsection{Cell Cycle Analysis}

A cell cycle analysis was performed as already described [20]. Briefly, HT-29 and HCT15 cells $(60,000$ cells $/ \mathrm{mL})$ were seeded and treated with PTX and PTX conjugates (half $\mathrm{IC}_{50}$ ). After $24 \mathrm{~h}$, cells were fixed with $70 \%$ ethanol at $4{ }^{\circ} \mathrm{C}$ for $15 \mathrm{~min}$. After fixation, cells were recovered by centrifugation and stained with $350 \mu \mathrm{L}$ PBS containing propidium iodide $(0.07 \mathrm{mg} / \mathrm{mL})$ and RNAse $(0.7 \mathrm{mg} / \mathrm{mL})$ for $15 \mathrm{~min}$ in the dark. Stained cells were analyzed by means of the Epics XL flow cytometer (Beckman Coulter, San Diego, CA, USA) using the CXP software (version 2.2, Beckmann Coulter, San Diego, CA, USA).

\subsection{Wound Healing Assay}

A wound healing assay was performed to analyze cell migration ability, as described before in [19]. Briefly, 10,000 cells were left adhered into 12-well plates for $48 \mathrm{~h}$. After seeding, a scratch in the cell monolayer was made using a pipette tip and washed with PBS. Cells were then treated with PTX and PTX conjugates (half $\mathrm{IC}_{50}$ ) for $24 \mathrm{~h}$. Cell migration in the wound area was assessed by means of a microscope $(10 \times$ magnification $)$ and Image J software. The percentage of scratch closure was calculated using the following Equation (1):

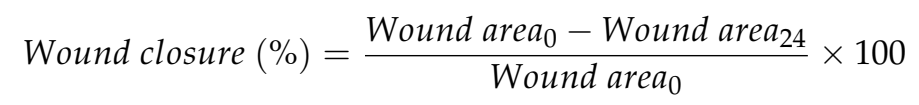




\subsection{1. $m R N A$ Expression Analysis by qRT-PCR}

To perform mRNA expression analysis, HT-29 and HCT-15 cells $\left(15 \times 10^{4}\right.$ cell/well $)$ were seeded into 6-well plates. After $24 \mathrm{~h}$, cells were treated with PTX and PTX conjugates (half $\mathrm{IC}_{50}$ ) for $24 \mathrm{~h}$. Total mRNA was extracted from cells by means of the TRIzol and Direct-zol RNA MiniPrep (Zymo Research, Irvine, CA, USA), following the manufacturers' instructions. qRT-PCR was performed by a QuantiNova SYBR Green RT-PCR Kit (Germantown, MD, USA) on an Eco Illumina Real-Time PCR system (Illumina Inc., San Diego, CA, USA) [21]. The sequences of the primers used in this study and their main characteristics are reported in Table 1 . Relative mRNA quantification was obtained according to the $\Delta \Delta \mathrm{Ct}$ method, using GAPDH as the housekeeping gene [22].

Table 1. qPCR primers used in this study.

\begin{tabular}{lcllc}
\hline Gene & Forward Sequence & Reverse Sequence & RefSeq & $\begin{array}{c}\text { Product } \\
\text { Length (Bp) }\end{array}$ \\
\hline p53 & GAGACCTGTGGGAAGCG & CGGGGACAGCATCAAAT & NM_001126118.2 & 123 \\
Bax & CACTGAAGCGACTGATGTCCC & CCGCCACAAAGATGGTCAC & NM_001291428.2 & 91 \\
Bcl2 & TGTGTGTGGAGAGCGTCAA & CAGCCCAGACTCACATCACCA & NM_000657.3 \\
TIMP-1 & GCTGTGAGGAATGCACAGTGTTT & GGACTGGAAGCCCTTTTCAGA & NM_003254.3 & 148 \\
TIMP-2 & TCTGTGACTTCATCGTGCCC & ATGTAGCACGGGATCATGGG & NM_003255.5 & 116 \\
MMP-2 & CATCCAGACTTCCTCAGGCGG & GGTCCTGGCAATCCCTTTGTATG & NM_004530.6 & 75 \\
GAPDH & ACATCAAGAAGGTGGTGAAGCA & GTCAAAGGTGGAGGAGTGGTT & NM_002046.7 & 119 \\
\hline
\end{tabular}

\subsection{ELISA Assay for VEGF Quantification}

VEGF release was measured in cell supernatants after 24 of treatment with PTX and PTX conjugates (half $\mathrm{IC}_{50}$ ) by means of a commercially available ELISA kit (ELH-VEGF, Raybiotech, Peachtree Corners, GA, USA), following the manufacturer's instructions. At the end of the procedure, the plates were read at $450 \mathrm{~nm}$ with multi-plate reader Victor Nivo (Perkin-Elmer Inc., Waltham, MA, USA), and the VEGF concentration was calculated from calibration curves plotted on log-log graphs.

\subsection{Pharmacokinetic Study in Mice}

All the procedures involving animals were conducted in agreement with national and international regulations (Directive 2010/63/EU), and suitable procedures were taken to minimize animal pain or discomfort. The procedures were reviewed and approved by the Ethical Committee of the University of Padova (OPBA), and by the Italian Ministry of Health, in the section for the care and use of laboratory animals (authorization no. 938/2016PR, obtained on August 4, 2016). The pharmacokinetic profiles of PTX-PEG, PTX-PEG-FA and PTX-PEG-(FA) 3 were determined in female Balb/C mice (25-30 g). A total of 30 mice were randomly divided into 2 groups of 15 animals. The samples were solubilized in phosphate buffered saline (PBS) pH 6.2. A dose of $10 \mathrm{mg} / \mathrm{kg}$ (PTX equiv.) was administered via the tail vein to mice anaesthetized with $5 \%$ isoflurane gas mixed with $\mathrm{O}_{2}$ in enclosed cages. At predetermined times, blood samples were withdrawn from the submandibular plexus. The blood samples were centrifuged at $1500 \times g$ for $15 \mathrm{~min}$. To $50 \mu \mathrm{L}$ of plasma, $350 \mu \mathrm{L}$ of $\mathrm{ACN}$ was added to obtain plasma proteins precipitation, and the resulting mixture was centrifuged at $20,000 \times g$ for $5 \mathrm{~min}$. Furthermore, $300 \mu \mathrm{L}$ of supernatant was collected and dried in speed-vac. The residue was dissolved in methanol and hydrolyzed with $0.2 \mathrm{NaOH}$ as reported above. PTX plasma concentration-vs-time data were analyzed by means of the 2.0 PkSolver, an add-in software for pharmacokinetic analysis in Microsoft Excel (Redmond, WA, USA). A bi-exponential equation was the best-fitting equation for the pharmacokinetic data obtained in this study. The main pharmacokinetic parameters were calculated from the coefficients and exponents of the best-fits by using standard formulae [23]. 


\subsection{Statistical Analysis}

The results obtained in this study were analyzed by the GraphPad Prism software (San Diego, CA, USA), version 8.0 and compared by a Student's $\mathrm{T}$ test or one-way ANOVA followed by the Tukey's post hoc test, when appropriate. Unless otherwise stated, data are reported as mean \pm S.E.M. $p$ values $<0.05$ were considered statistically significant.

\section{Results}

\subsection{Synthesis and Characterizarion of PTX-PEG, PTX-PEG-FA and PTX-PEG-(FA) 3 Conjugates}

Two PEG conjugates carrying PTX and a different loading of FA were prepared starting from Boc-NH-PEG5k-NHS. The synthesis of the conjugates PTX-PEG-FA and PTX-PEG$(\mathrm{FA})_{3}$ was performed as reported in Figure 1 and Figure $\mathrm{S} 1$ and it required three main steps: the synthesis of PEG-FA, the succinylation of the PTX hydroxyl group in the $2^{\prime}$ position and the binding of SPTX to $\mathrm{H}_{2} \mathrm{~N}$-PEG-FA or $\mathrm{H}_{2} \mathrm{~N}$-PEG-(FA) ${ }_{3}$.

The modification of FA with N-Boc-1,5-diaminopentane was monitored by RP-HPLC and the formation of the mono-derivative of FA was verified through ESI-TOF mass spectrometry (Figure S2). The applied reaction conditions have avoided the derivatization of both carboxylic groups of FA, generating the undesired side product FA-(DAP- $\left.\mathrm{NH}_{2}\right)_{2}$. FA-DAP-NH $\mathrm{N}_{2}$ formation was monitored by RP-HPLC and confirmed by ESI-TOF mass spectrometry (Figure S3). The collected intermediate was a mixture of free FA and FADAP- $\mathrm{NH}_{2}$, and the number of amino groups was calculated to be $64.5 \%$ on the basis of the Snaider-Sobocisky assay. Free FA could not react with Boc-PEG-NHS and consequently its removal was postponed after the synthesis of Boc-PEG-FA. The binding of FA-DAP-NH $\mathrm{N}_{2}$ to PEG and the absence of free FA or FA-DAP- $\mathrm{NH}_{2}$ were checked by RP-HPLC. The MALDITOF analysis also confirmed the formation of PEG-FA derivatives (Figures S4 and S5). After purification, the products were characterized by ${ }^{1} \mathrm{H}-\mathrm{NMR}$ (Figure S6 panel A and Figure S7 panel A). The linear derivative Boc-PEG-FA showed the conjugation with one molecule of FA, on the basis of ${ }^{1} \mathrm{H}-\mathrm{NMR}$ evaluation, while the coupling of the PEG dendron to FA-DAP- $\mathrm{NH}_{2}$ resulted in about three molecules of FA for the PEG unit (Table 1). The modification of PTX with the succinic spacer was verified by ESI-TOF mass spectrometry (Figure S8) and ${ }^{1} \mathrm{H}-\mathrm{NMR}$ (Figure S9). After the removal of the Boc protecting group from PEG-FA intermediates (Figure S6 panel B and Figure S7 panel B), SPTX was conjugated to the free amino group of $\mathrm{H}_{2} \mathrm{~N}$-PEG-FA and $\mathrm{H}_{2} \mathrm{~N}$-PEG-(FA) $)_{3}$ via activation of the carboxylic group of the succinic spacer. Purified PTX-PEG-FA and PTX-PEG-(FA) ${ }_{3}$ were characterized by ${ }^{1} \mathrm{H}-\mathrm{NMR}$ (Figure S6 panel C and Figure S7 panel C) showing the characteristic signals of PTX together with those of the succinic spacer, PEG and folic acid. The synthesis and the characterization of non-targeted PTX-PEG were reported in Supplementary Materials (Figures S10 and S11). The reaction yields of SPTX coupling were similar for all the conjugates and are listed in Table 1. The content of free drugs in PTX-PEG, PTX-PEG-FA and PTX-PEG-(FA) $)_{3}$ was found to be less than $1.5 \%$ with respect to the total drug amounts, as determined by RP-HPLC. The loading $w / w \%$ of PTX of each conjugate is reported in Table 2.

Table 2. PTX-PEG, PTX-PEG-FA and PTX-PEG-(FA)3 reaction yields $(w / w) \%$, loading $\% w / w$ of FA and PTX and mean hydrodynamic diameter of polymeric structure in PBS at pH 7.4.

\begin{tabular}{ccccc}
\hline Conjugate & \% of Free PTX & $\begin{array}{c}\text { FA Loading } \\
(\mathbf{m o l} \%)\end{array}$ & $\begin{array}{c}\text { PTX Loading } \\
(\boldsymbol{w} / \boldsymbol{w} \boldsymbol{\%})\end{array}$ & $\begin{array}{c}\text { Hydrodynamic } \\
\text { Diameter }(\mathbf{n m})\end{array}$ \\
\hline PTX-PEG & 1.33 & - & $9.11 \pm 0.1$ & $137.4 \pm 1.8$ \\
PTX-PEG-FA & 1.47 & 1 & $10.27 \pm 1.02$ & $140.4 \pm 0.18$ \\
PTX-PEG-(FA) & 0.79 & 3 & $8.53 \pm 0.2$ & $130.1 \pm 2.28$ \\
\hline
\end{tabular}




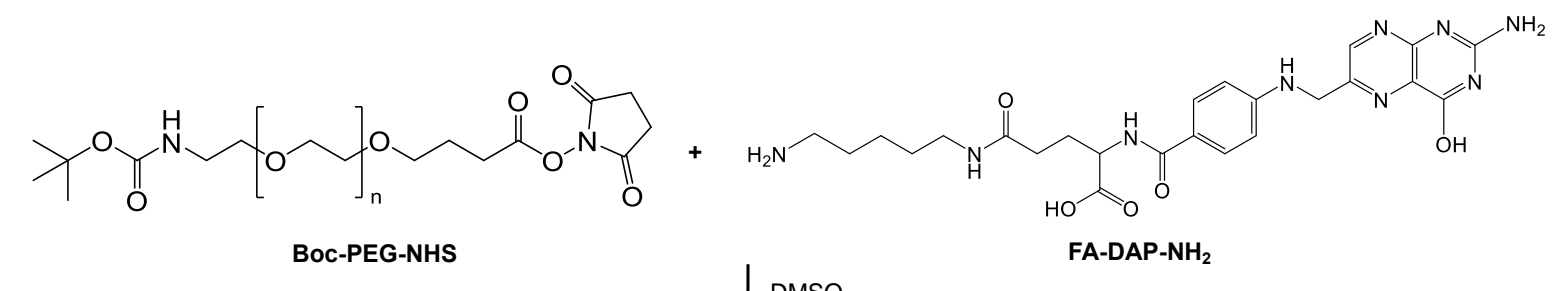<smiles>CC(C)(C)OC(C)(C)CNC(=O)OC(C)(C)COC(C)(C)CCCC(=O)NCCCCCNC(O)CCC(NC(O)c1ccc(NCc2cnc3nc(N)nc(O)c3n2)cc1)C(=O)O</smiles><smiles>CC(C)(CN)OCCC(C)(C)OCCCC(=O)NCCCCCNC(=O)CCC(NC(=O)c1ccc(NCC2CN3N=C(N)N=C(O)C3N2)cc1)C(=O)O</smiles>

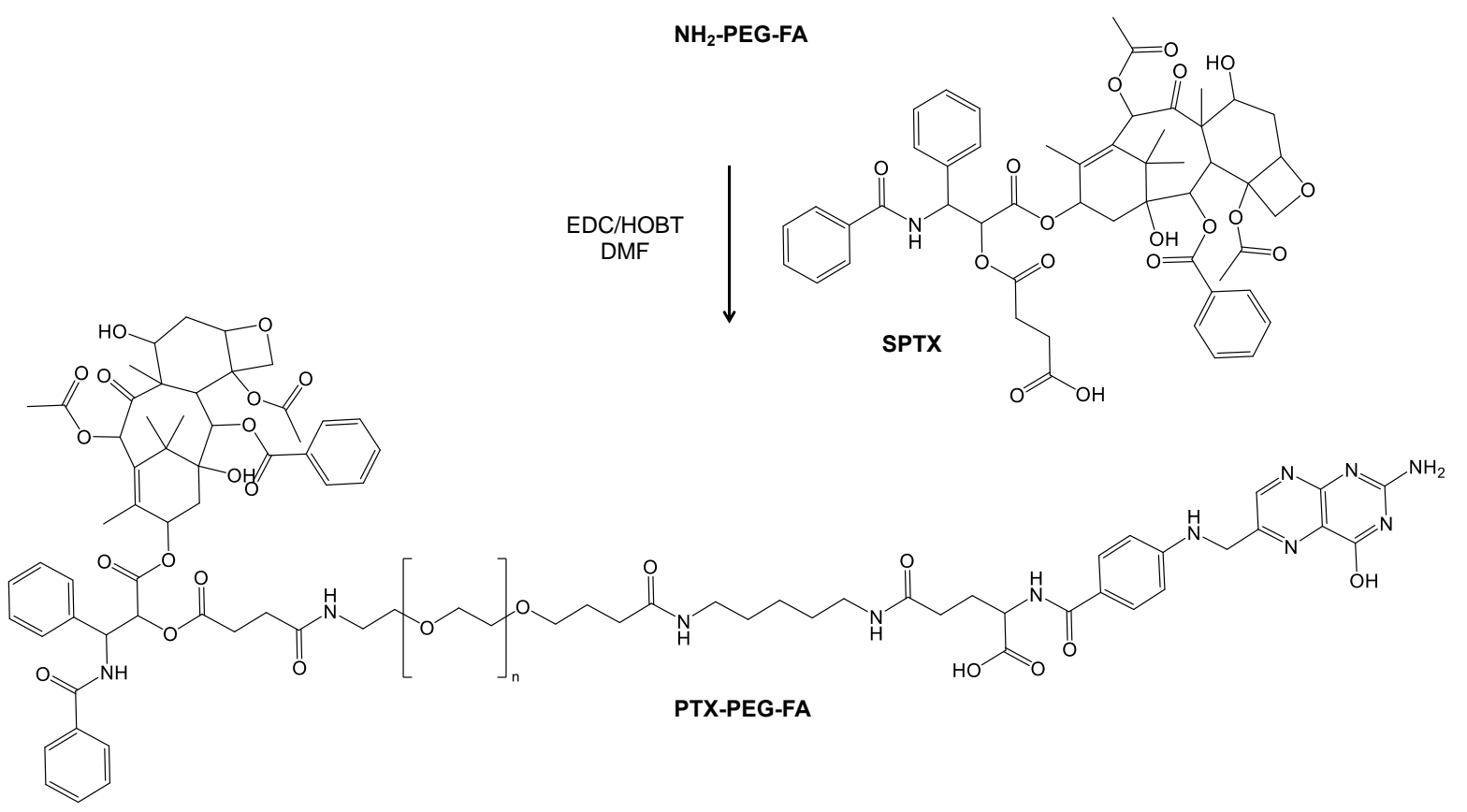

Figure 1. Synthesis of PTX-PEG-FA.

Beyond the chemical structure and the control of the composition, another important aspect is the conformation of the conjugates in a solution that may affect body biodistribution and clearance. Being amphiphilic, an FA-targeted PEG-PTX conjugate can arrange supramolecular nanoassemblies as shown by DLS measurements (Table 1), with sizes in the 130-140 nm range (Figure S12). The stability of PEG-PTX conjugate nanoassemblies in the solution was monitored by DLS at $37^{\circ} \mathrm{C}$ for up to $24 \mathrm{~h}$. PTX was linked to the polymer through an ester linkage which undergoes hydrolysis, thus releasing the drug. The size of PTX-PEG and PTX-PEG-FA nanoassemblies started to increase after about four hours of incubation as a consequence of PTX released from the conjugates, which destabilized the system, while the micelles of PTX-PEG-(FA) $)_{3}$ were stable for a prolonged time (Figure 2). For PTX-PEG-(FA) 3 , the structure of the micelles was maintained up to $24 \mathrm{~h}$, suggesting a slower hydrolysis rate of the drug. We could speculate that despite the fact that a certain 
degree of PTX was hydrolyzed, such PTX molecules were retained in the inner core of the nanoassemblies, due to the high hydrophobicity of the drug.

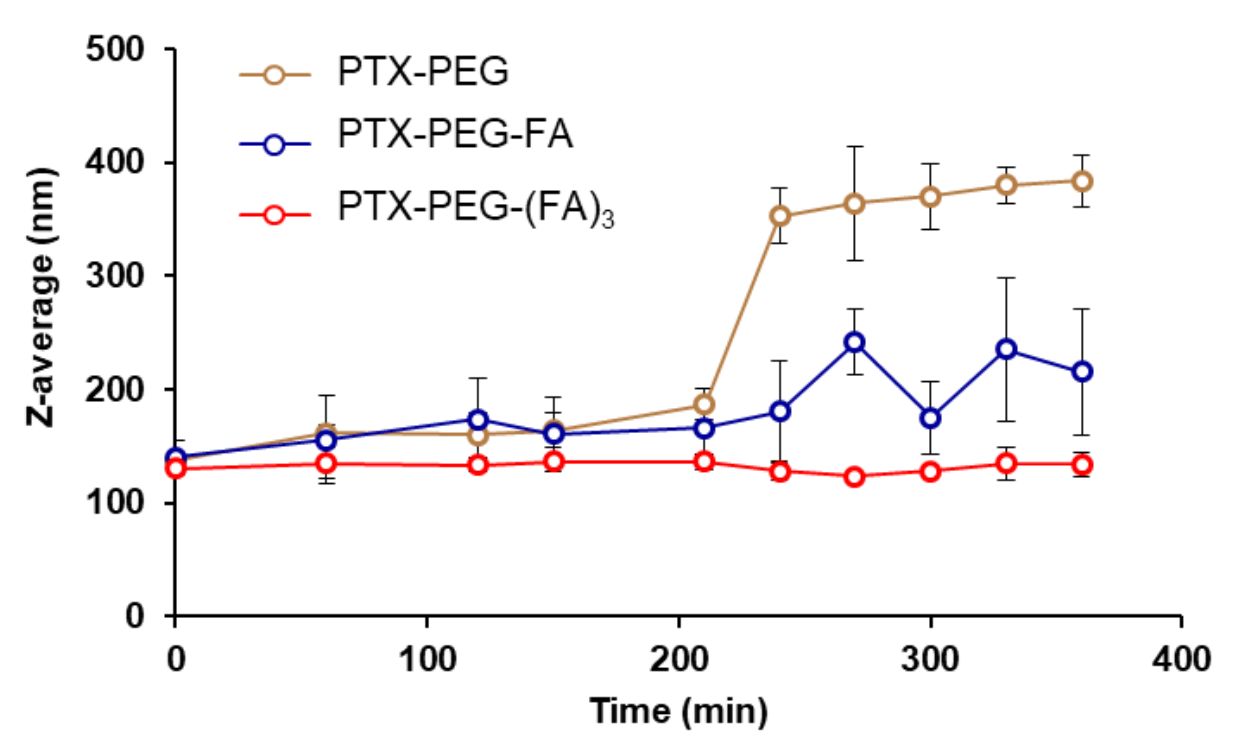

Figure 2. Evaluation of PTX-PEG, PTX-PEG-FA and PTX-PEG-(FA) $)_{3}$ nanoassemblies stability in PBS buffer at $\mathrm{pH} 7.4,37^{\circ} \mathrm{C}$. The size of the micelles was monitored using by DLS.

\subsection{PTX-PEG-FA Conjugates Induced Cytotoxicity on FR-Postive HT-29 Cells}

The conjugates were tested in two CRC cell lines with different expressions of the FA receptor (Figure S13). In FR-positive HT-29 cells, both the targeted PTX conjugates were more active compared to FR-negative HCT-15 cells, whereas PTX and PTX-PEGinduced cytotoxicity was similar in the two cell lines (Figure 3). However, a slight increase $(p<0.05)$ of PTX-PEG IC 50 values could be observed in HCT-15 cells with respect to HT-29. Furthermore, in HT-29 cells the cytotoxic activity of the PTX-PEG-(FA) $)_{3}$ conjugate was similar to that of unconjugated PTX and PTX-PEG, whereas a slight but significant $(p<0.05)$ drop of activity was observed for the PTX-PEG-FA conjugate with respect to PTX and the PTX-PEG conjugate (Figure 3, Table 3). However, no statistical difference could be observed between the activities of the two targeted conjugates in HT-29 cells (Figure 4). In HCT-15 cells, the conjugation of PTX caused a significant drop of its activity, especially for the PTX-PEG-(FA) $)_{3}$ conjugate, which was less cytotoxic not only than unconjugated PTX and PTX-PEG $(p<0.0001)$, but also than PTX-PEG-FA $(p<0.001)$.
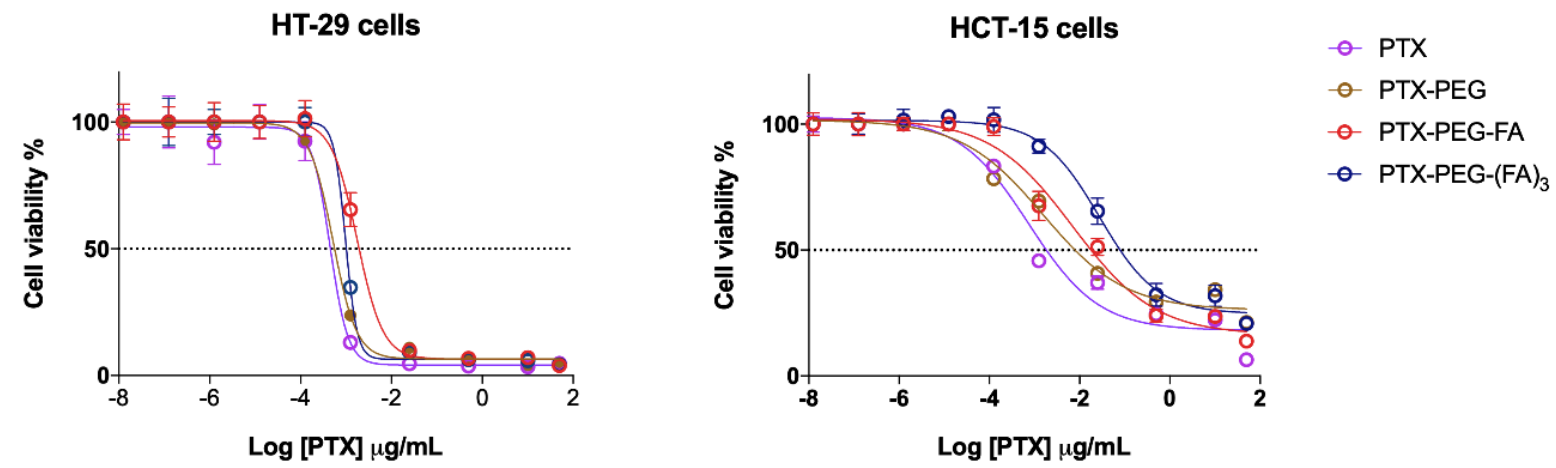

Figure 3. Cytotoxicity of PTX and PTX conjugates in FR-positive (HT-29) and FR-negative (HCT-15) cells. The results are the mean of three independent experiments, each performed in triplicate. 
Table 3. $\mathrm{IC}_{50}$ values (ng/mL PTX).

\begin{tabular}{|c|c|c|c|c|}
\hline Cell Line & PTX & PTX-PEG & PTX-PEG-FA & PTX-PEG-(FA) ${ }_{3}$ \\
\hline HТ-29 & $0.444 \pm 0.123$ & $0.518 \pm 0.241$ & $1.766 \pm 0.791^{\#}$ & $0.979 \pm 0.151$ \\
\hline НСТ-15 & $0.750 \pm 0.265$ & $1.580 \pm 0.454$ * & $7.153 \pm 1.423 * *, \#$ & $27.69 \pm 4.12 * * *, \# \# \# \#, \S \S \S$ \\
\hline
\end{tabular}

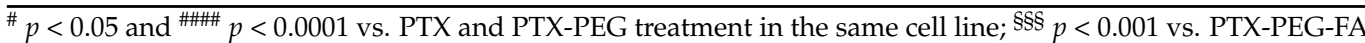
treatment in the same cell line; ${ }^{*} p=0.0231$ vs. HT-29 cells treated with PTX-PEG; ${ }^{* *} p=0.0017$ vs. HT-29 cells treated with PTX-PEG-FA; ${ }^{* * *} p=0.0004$ vs. HT-29 cells treated with PTX-PEG-(FA) $)_{3}$.
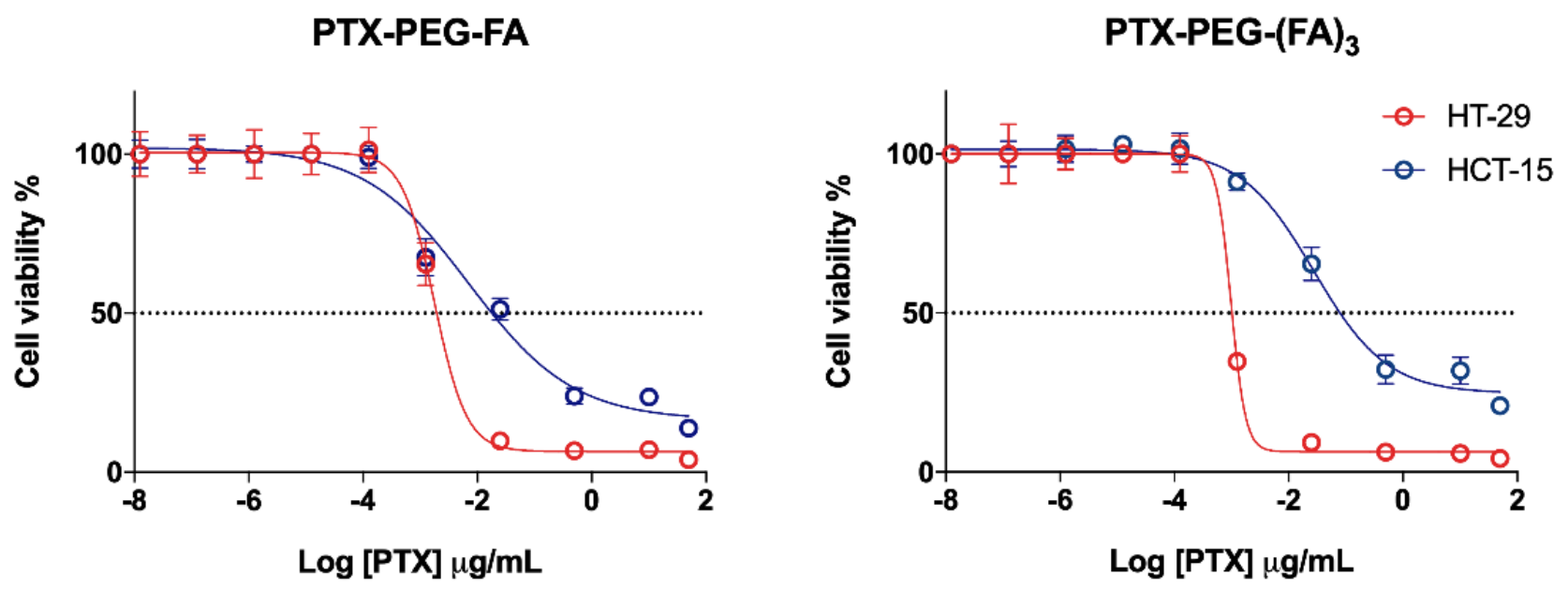

Figure 4. Graphical comparison between the cytotoxicity of the two targeted conjugates in FR-positive (red) and FR-negative (blue) cells.

\subsection{PTX-PEG-(FA) $)_{3}$ Induces G1/M Phase Cell Cycle Arrest in HT-29 Cells}

In order to obtain additional information about PTX-PEG-FA conjugates on HT-29 and HCT-15 cells, we investigated by flow cytometry the cell cycle distribution after $24 \mathrm{~h}$ of treatment at the half $\mathrm{IC}_{50}$ values reported in Table 3. As shown in Figure 5A, the percentage of HT-29 cells in G2/M phase were dramatically increased only by the PTX-PEG-(FA) 3 conjugate in these experimental conditions, from $20 \%$ of the control to $85 \%$ for HT-29 cells treated with this conjugate. Conversely, no effect was observed in HCT-15 cells. These findings indicate that PTX-PEG-(FA) ${ }_{3}$ displays a peculiar cytotoxicity towards FR-positive HT-29 cells, by arresting the cell cycle in the G2/M phase. Accordingly, only PTX-PEG$(\mathrm{FA})_{3}$ caused a significant increase of the mRNA expression of the two pro-apoptotic genes p53 and Bax, and a decreasing tendency of the anti-apoptotic gene Bcl-2. This effect was not observed in HCT-15 cells for which, in accordance with the data about cell cycle arrest, the treatments did not change the expression of the tested anti- and pro-apoptotic genes.

\subsection{PTX-PEG-FA Conjugates Inhibit Migration of HT-29 Cells}

Since the generation of metastasis is a peculiar feature of colorectal cancer [24], we performed a wound healing assay in HT-29 and HCT-15 cells treated with PTX or its conjugates (half $\mathrm{IC}_{50}$ ) for $24 \mathrm{~h}$. In Figure 6, it is clearly shown that PTX and all the tested conjugates were able to reduce the migration of HT-29 cells. However, only PTX-PEG-(FA) 3 was significantly more effective than PTX in reducing HT-29 migrative capacity in these experimental conditions. In contrast, only free PTX significantly reduced the migration of FR-negative HCT-15 cells.

To confirm the results of the wound healing assay, we measured the vascular endothelial growth factor (VEGF) release from HT-29 and HCT-15 cells in cell supernatants, because it is well-known that VEGF is a key player in the migration and invasion of cancer cells [25]. In Figure 7 , it is shown that PTX and PTX-PEG-(FA) $)_{3}$ significantly reduced VEGF release 
from HT-29 cells, confirming their inhibiting effect on the migration of FR-positive cells, whereas VEGF release from FR-negative cell migration was reduced only by free PTX.

Finally, since invasion and metastasis are processes modulated by matrix metalloproteases (MMP) and their inhibitors TIMPs, we analyzed the effect of PTX and its conjugates on the mRNA expression of three genes known to participate in the migration and invasiveness of colon cancer cells., i.e., TIMP1, TIMP2 and MMP2 [26]. Figure 8 shows that PTX-conjugates can upregulate the mRNA expression of TIMP2 and downregulate that of TIMP1 and MMP2 only in FA-positive HT-29 cells. This effect on genes involved in migration and invasiveness is more evident in cells treated with the conjugate PTX-PEG-(FA) $)_{3}$.

A
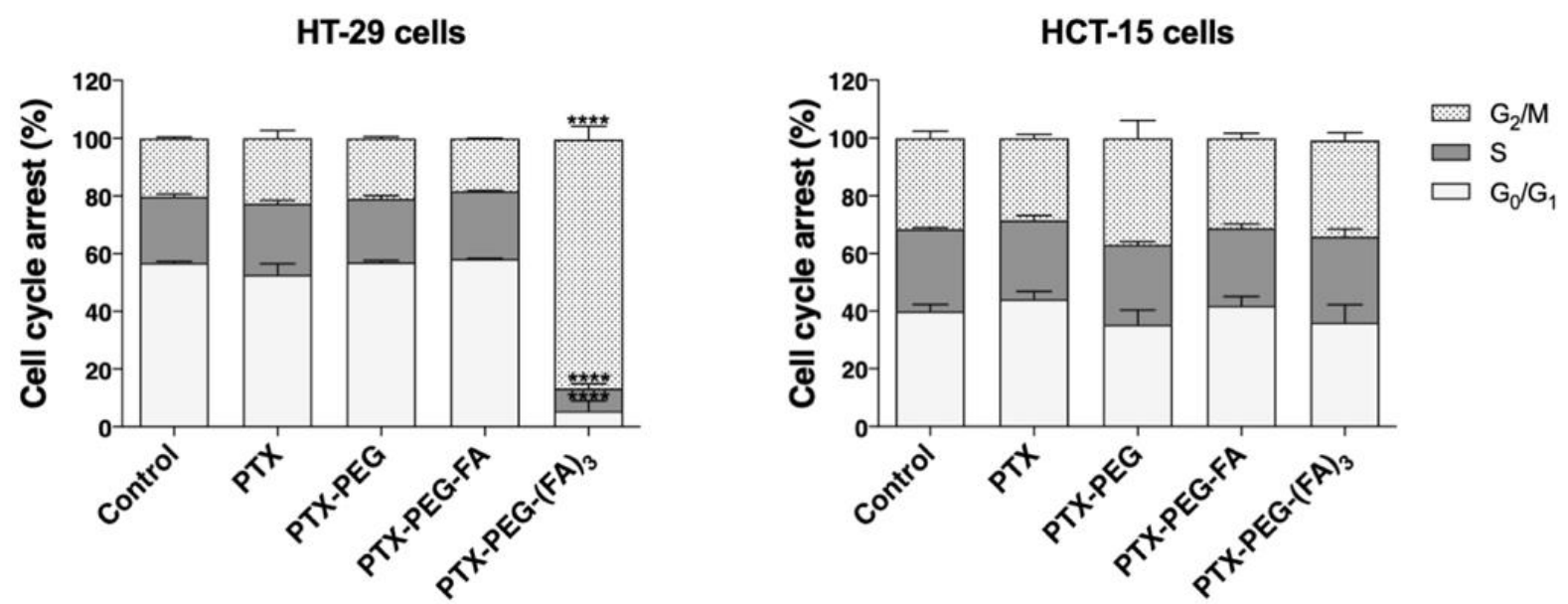

B

HT-29 cells
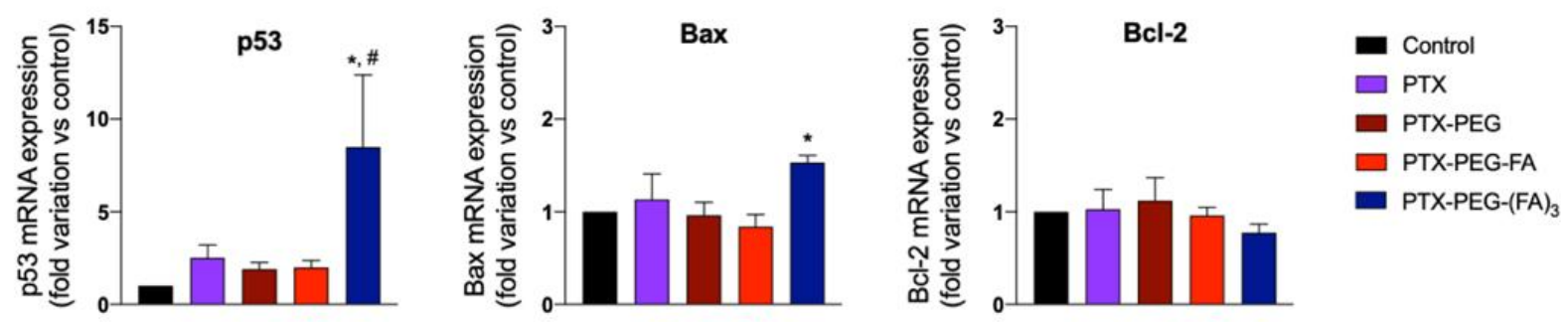

C

\section{HCT-15 cells}
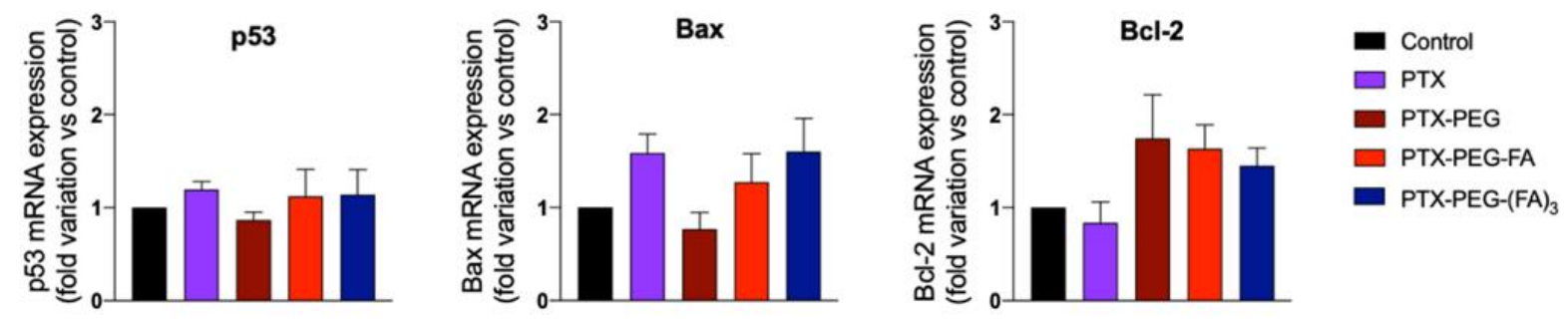

Figure 5. (A) Cell cycle distribution of HT-29 and HCT-15 cells exposed to PTX and PTX conjugates. ${ }^{* * * *} p<0.0001$ vs. all the other treatments. Effect of PTX and PTX conjugates on the mRNA expression of the pro-apoptotic genes p53 and Bax, and the anti-apoptotic gene Bcl-2 on HT-29 (B) and HCT-15 (C) cells. ${ }^{*} p<0.05$ vs. control, ${ }^{*} p<0.05$ vs. cells treated with PTX. The results are the mean of three independent experiments, each performed in triplicate. 
A
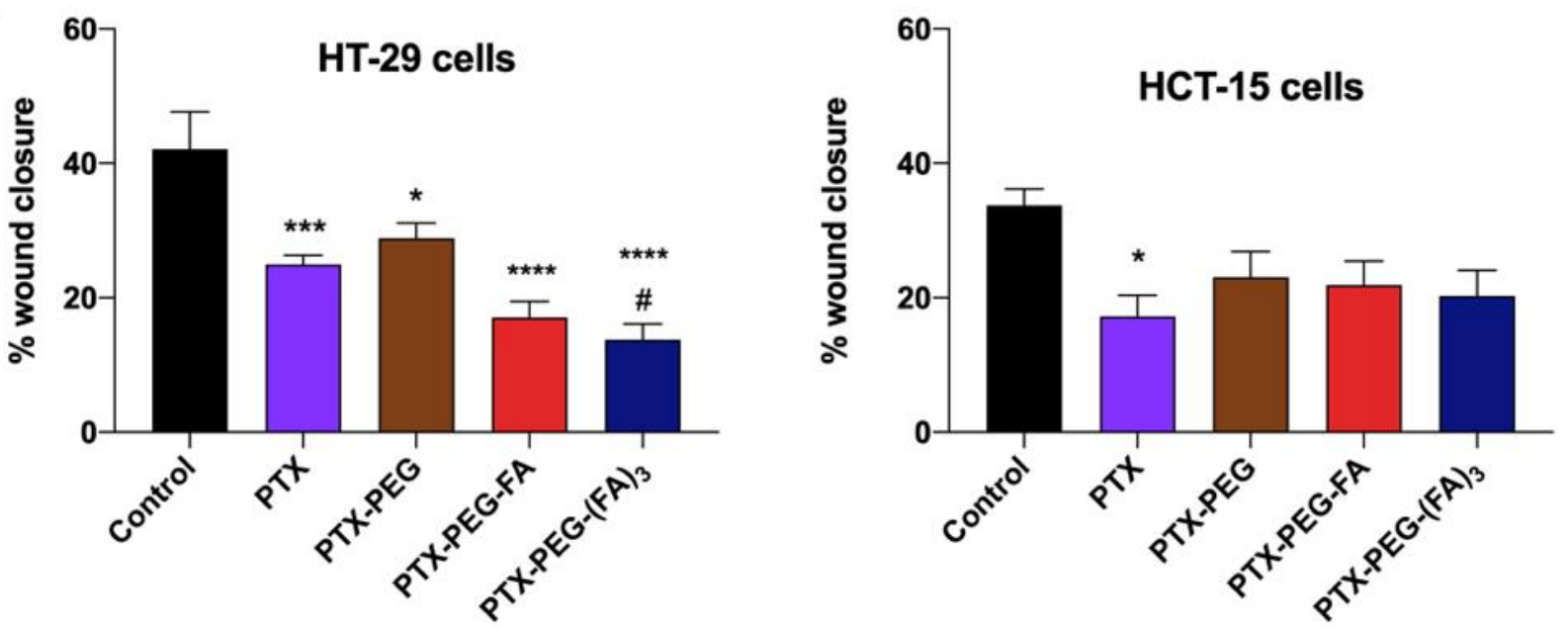

\section{B}

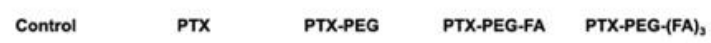

$\mathbf{O h}$
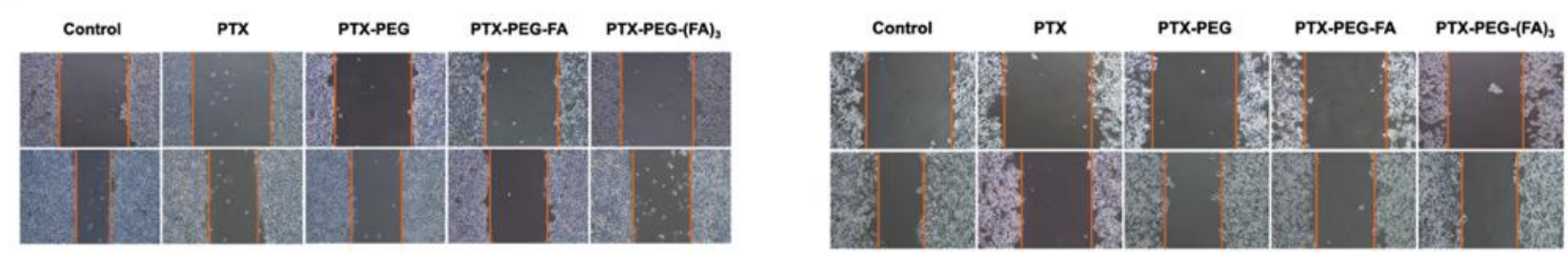

Figure 6. Wound healing assay in the CRC cell lines HT-29 and HCT-15. (A) Quantitative analysis of scratch wound healing assay after a $24 \mathrm{~h}$ treatment with NEM or CP (half $\mathrm{IC}_{50} / 48 \mathrm{~h}$ ). (B) Representative images of the scratch wound healing (magnification 10×). The results are the mean of three independent experiments. ${ }^{*} p<0.05,{ }^{* * *} p<0.001,{ }^{* * * *} p<0.0001$ vs. untreated control cells; $\#<<0.05$ vs. cells treated with PTX.
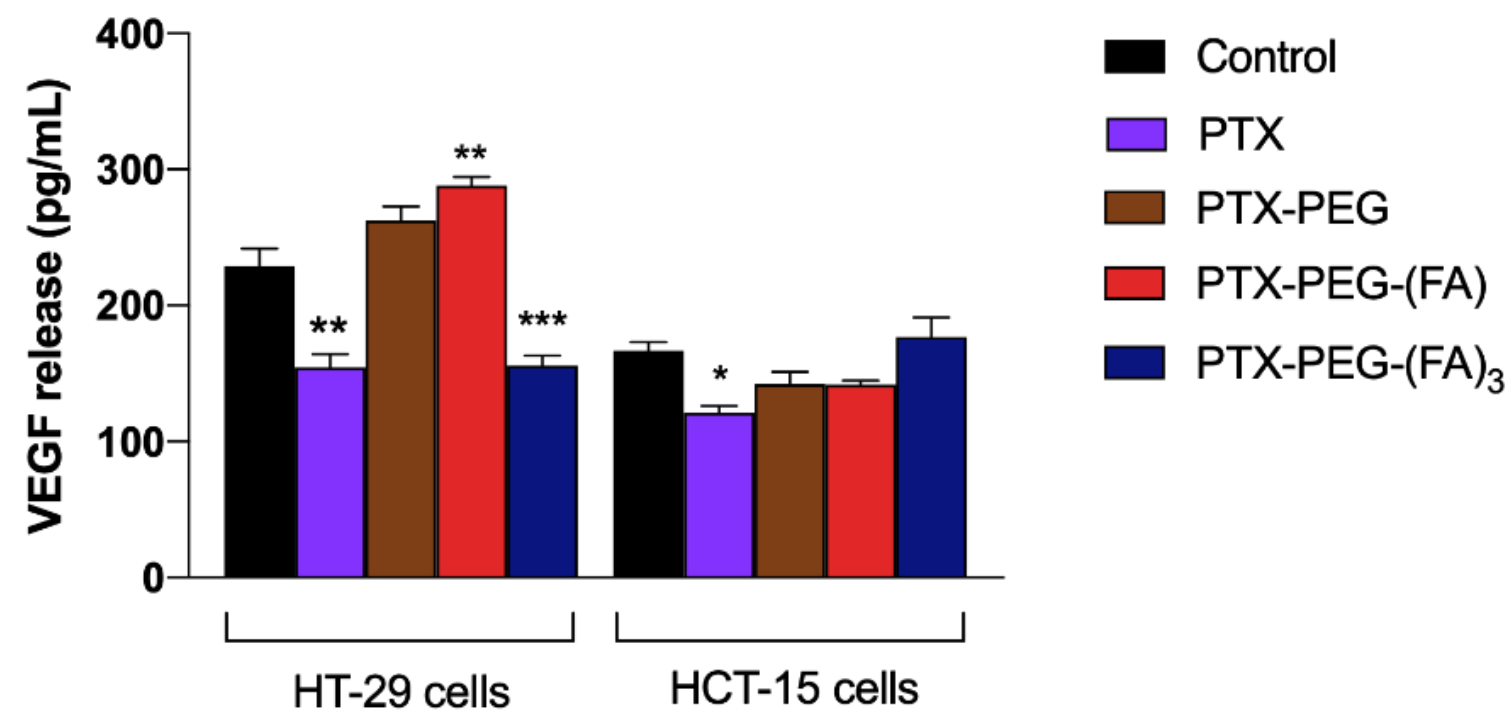

Figure 7. VEGF release from HT-29 and HCT-15 cells exposed to PTX and PTX-PEG-FA conjugates. ${ }^{*} p<0.05,{ }^{* *} p<0.01$, $* * * p<0.001$ vs. control untreated cells. The results are the mean of three independent experiments, each performed in duplicate. 
A

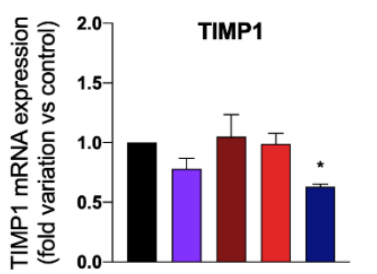

B

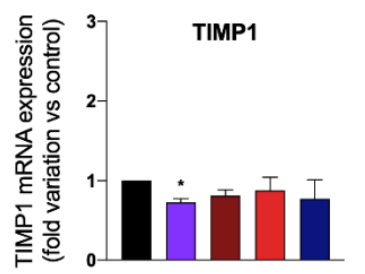

HT-29 cells
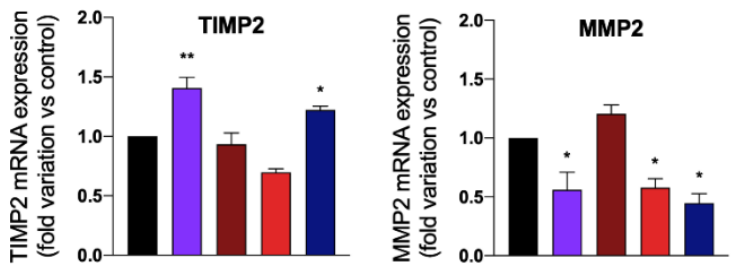

- Control

$\square$ PTX

- PTX-PEG

$\square$ PTX-PEG-FA

- PTX-PEG-(FA) ${ }_{3}$

HCT-15 cells
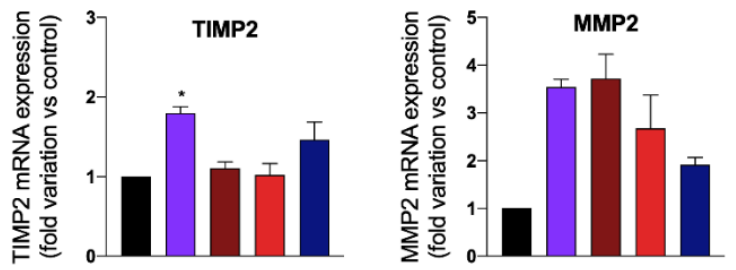

- Control

$\square$ PTX

- PTX-PEG

$\square$ PTX-PEG-FA

- PTX-PEG-(FA)

Figure 8. Effect of PTX and PTX conjugates on the mRNA expression of the TIMP1, TIMP2 and MMP2 on HT-29 (A) and HCT-15 (B) cells. ${ }^{*} p<0.05,{ }^{* *} p<0.01$, vs. control cells. The results are the mean of three independent experiments, each performed in triplicate.

\subsection{Pharmacokinetic Studies in Mice}

The pharmacokinetics of PTX-PEG, PTX-PEG-FA and PTX-PEG-(FA) 3 were studied in Balb/C mice after IV administration (Figure 9, Table 4). The two FA-targeted PTX conjugates showed a significant half-life prolongation with respect to that of PTX. For the pharmacokinetic profile of PTX we refer to our previous study in which the PTX plasma concentration fell below the limit of detection after $30 \mathrm{~min}$ post injection with $\mathrm{at}_{\frac{1}{2} \beta}$ of 15 min [8]. In particular, PTX-PEG-(FA) $)_{3}$ exhibited a great increase of the $t_{\frac{1}{2} \beta}$, reaching a value of about $5 \mathrm{~h}$, and caused an increase of PTX bioavailability, since its AUC showed an approximate 2 -fold increase with respect to that of the linear targeted derivative.

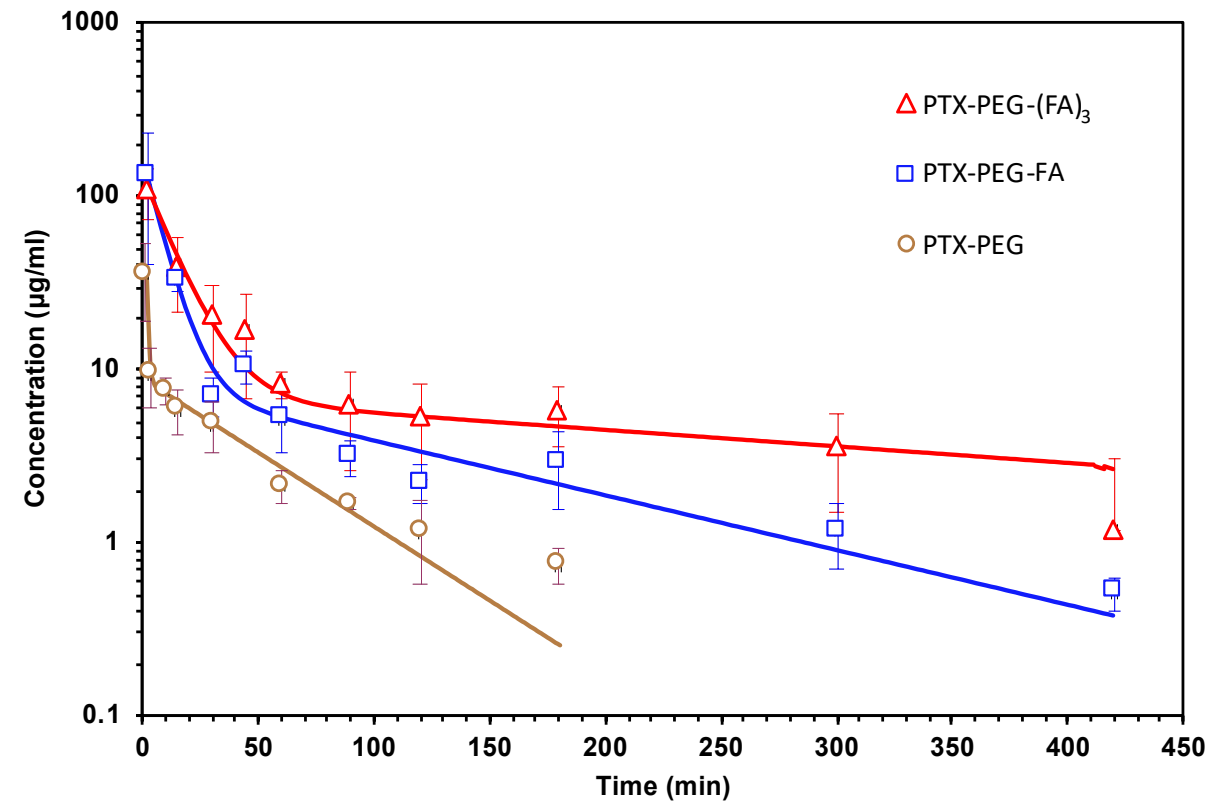

Figure 9. Pharmacokinetic profiles of PTX-PEG-FA and PTX-PEG-(FA) $)_{3}$ in Balb/C mice after IV administration of $10 \mathrm{mg} / \mathrm{kg}$ (PTX equiv.). 
Table 4. Main pharmacokinetic parameters of PTX-PEG-FA and PTX-PEG-(FA) $)_{3}$ after IV administration of $10 \mathrm{mg} / \mathrm{kg}$ (PTX equiv.) in Balb/C mice.

\begin{tabular}{cccccc}
\hline Sample & $\begin{array}{c}\mathbf{t}_{\frac{1}{2} \boldsymbol{\alpha}} \\
(\mathbf{m i n})\end{array}$ & $\begin{array}{c}\mathbf{t}_{\frac{1}{2} \boldsymbol{\beta}} \\
(\mathbf{m i n})\end{array}$ & $\begin{array}{c}\text { AUC 0-inf } \\
(\boldsymbol{\mu} \mathbf{g} \mathbf{~ m i n} / \mathbf{m L})\end{array}$ & $\begin{array}{c}\mathbf{C L} \\
(\mathbf{m L} / \mathbf{m i n})\end{array}$ & $\begin{array}{c}\mathbf{V d} \\
(\mathbf{m L})\end{array}$ \\
\hline PTX-PEG & 0.46 & 35.2 & 1566.3 & 0.15 & 6.6 \\
PTX-PEG-FA & 5.62 & 95.4 & 2438.5 & 0.12 & 8.2 \\
PTX-PEG-(FA) & 8.94 & 313.8 & 4740.78 & 0.08 & 7.6 \\
\hline
\end{tabular}

\section{Discussion}

Targeted drug delivery systems have been proposed as a key strategy for achieving the selective transport of cytotoxic cargos from the site of injection to the cancer cells. Ligand-mediated targeting alone might not always be sufficient for a targeted delivery of proper amounts of drugs at the site of action, and neither is the EPR effect alone for those nanomedicines that focus only on the increment of sizes for exploiting passive targeting. Consequently, to maximize as much as possible the effectiveness of these drug delivery systems, joining the positive features of both targeting strategies, commonly defined as active and passive targeting, is necessary. Here we seek to investigate this possibility by studying polymeric drug conjugates targeted with FA for active targeting, which showed an increased size in solution for a better pharmacokinetic and the desired tumor accumulation through the EPR effect.

At the basis of these FA-targeted conjugates there is a heterobifunctional PEG that presents two different reactive groups at the chain ends, thus offering the possibility of coupling at separate sites the drug and the targeting agent for a defined chemical structure of the conjugates. The FA-targeted PEG-PTX conjugates were developed with a precise composition to allow the investigation of the role of each component in terms of activity with respect to cell lines with different expression levels of the target, i.e., the FA receptor (Figure S11). PEG with a molecular weight of 5kDa was selected because such size ensures the solubilization in water of the hydrophobic PTX and allows the formation of nanoassemblies in the solution, as we already reported with alendronate as targeting agent [8]. The FA-targeted PEG-PTX conjugate with an increased payload of FA was prepared by synthetizing a dendron structure based on $\beta$-glutamic acid as the branching unit, with the aim of improving the targeting efficiency and selectivity of the conjugate towards the cancer cells overexpressing the FA receptor. The synthesis of a dendron structure offers the possibility to design a polymer drug conjugate with the desired targeting characteristics. FA was linked to carboxylic units of PEG through the 1,5-diaminopentane spacer, to increase the mobility of FA and favor the binding with its receptor.

The conjugates were obtained in good yields and resulted in completely soluble aqueous buffers, contrary to PTX that, in clinical use, needs to be solubilized in the hydrophobic vehicle Cremophor-EL. PTX-PEG, PTX-PEG-FA and PTX-PEG-(FA) 3 were tested in two human colorectal adenocarcinoma cell lines with different expressions of the FA receptor for evaluating whether the increased payload of the targeting agent in PTX-PEG-(FA) 3 could have an impact on the cytotoxic activity. $\mathrm{IC}_{50}$ values (Table 2 ) showed that overall FA-targeted PEG-PTX conjugates were more active in FR-positive HT-29 cells than in FR-negative HCT-15 cells. This result positively confirmed that these conjugates can be selectively toxic towards target cells while at the same time sparing the cells not expressing the target. Furthermore, by comparing the two FA-targeted PEG-PTX conjugates we can affirm that the selective cytotoxicity towards target cells (HT-29) with respect to the cytotoxicity in non-target cells (HTC-15) was augmented by increasing the number of targeting molecules per polymer chain. In fact, PTX-PEG-FA was 4-fold more active in HT-29 compared to HCT-15 while PTX-PEG-(FA) 3 , under the same conditions, was more than 28-fold more cytotoxic. These ratios correspond to just 3-fold for PTX-PEG and less than 2-fold for PTX. Consequently, apart from the relevance of the presence of active 
targeting, this study also points to the targeting ligand payload with the polymer-drug conjugate. Furthermore, PTX-PEG-(FA) $)_{3}$, besides increasing significantly PTX cytotoxicity due to the enhanced target capacity, showed a peculiar effect on the cell cycle, since it was able to arrest $85 \%$ of the cells in the G2/M phase. To confirm this observation, we performed a qPCR analysis to measure the expression of three genes involved in apoptosis, namely the pro-apoptotic p53 and Bax and the anti-apoptotic Bcl-2, thereby observing that only PTX-PEG-(FA) 3 significantly affects their expression by increasing both p53 and Bax. Interestingly, the activation of p53 has been linked to the arrest of the cell cycle in the G2/M phase and to an enhancement of efficacy of antimitotic drugs including PTX [27]. It is possible to hypothesize that the targeting effect of the three FA molecules is particularly efficient and yielded a PTX concentration inside the cells, at the end of the incubation, which was sufficient to exert the observed effect on cell cycle distribution and mRNA expression [28].

In addition, we investigated whether the generation of these PTX-PEG-FA conjugates could have a specific effect on migration and invasiveness of FR-positive colorectal cancer cells. Interestingly, only PTX-PEG-(FA) ${ }_{3}$ could both reduce HT-29 cell migration, as demonstrated in the wound healing assays, and decrease the release of the pro-metastatic agent VEGF. A peculiar effect of PTX-PEG-(FA) $)_{3}$ was observed also on the mRNA expression of the tissue inhibitor of metalloproteinases (TIMP)1, a prognostic marker of progression and metastasis of colon cancer [29], whose mRNA expression was decreased only by this PTX conjugate. Based on their relevance in colorectal cancer invasion [26], we also evaluated the mRNA expression of the matrix metalloproteinase 2 (MMP2) and its inhibitor TIMP2. It has been demonstrated that MMP2 is upregulated in invasive colorectal cancers and participates in the metastatic process by degrading $\beta 1$ integrins, thereby decreasing cell adhesion and enhancing their motility [30]. Accordingly, the reduced expression of the MMP2 inhibitor TIMP2 correlates with colorectal cancer invasion and a worse prognosis [31]. We found that PTX and PTX-PEG-(FA) $)_{3}$ can upregulate the mRNA expression of TIMP2 and downregulate that of MMP2, thereby confirming their effect on colon cancer cell migration and invasiveness. Furthermore, PTX-PEG-(FA) ${ }_{3}$ demonstrated the most promising features also in vivo since, as expected, it showed an improvement of the PTX pharmacokinetic profile which was superior to that obtained by the conjugate with only one FA molecule. This led to an increased and prolonged in vivo drug exposure and suggested a potential accumulation in tumors by the EPR effect.

\section{Conclusions}

The obtainment of a well-defined targeted polymer-drug conjugate in which the targeting moiety is spatially separated from the cytotoxic drug is not trivial and passes through an accurate drug design. Only an accurate study of each conjugate component will lead to the development of drug-polymer conjugates with improved and selective cytotoxicity.

Supplementary Materials: The following are available online at https://www.mdpi.com/article/10 .3390/pharmaceutics13070929/s1: Figure S1: Scheme of synthesis of PTX-PEG-(FA) ${ }_{3}$; Figure S2: Mass spectrum of Boc-DAP-FA; Figure S3: Mass spectrum of FA-DAP-NH2; Figure S4: Mass spectrum of Boc-PEG-FA; Figure S5: Mass spectrum of Boc-PEG-FA 3 ; Figure S6: 1H-NMR spectra of Boc-PEG-FA, $\mathrm{H}_{2}$ N-PEG-FA and PTX-PEG-FA; Figure S7: Comparison of $1 \mathrm{H}-\mathrm{NMR}$ of Boc-NH-PEG-(FA) $)_{3}, \mathrm{H} 2 \mathrm{~N}-$ PEG-(FA) 3 , and PTX-PEG-(FA) ${ }_{3}$; Figure S8: Mass spectrum of SPTX; Figure S9: 1H-NMR spectra of PTX and SPTX; Figure S10: Synthesis of PTX-PEG; Figure S11: 1H-NMR spectra of mPEG-NH 2 (A) and PTX-PEG (B); Figure S12: Size distribution by DLS of PTX-PEG (A), PTX-PEG-FA (B) and PTX-PEG-(FA) ${ }_{3}$; Figure S13: Expression of Folic Acid receptor on HT-29 and HCT-15 cells.

Author Contributions: Conceptualization, G.P.; methodology, A.G., G.M., D.G., T.T., M.S., S.D.M.; investigation, A.G., G.M., D.G., S.D.M.; resources, G.P.; data curation, G.P., S.D.M.; writing-original draft preparation, A.G., S.D.M.; writing—review and editing, G.P.; supervision, G.P.; funding acquisition, G.P. All authors have read and agreed to the published version of the manuscript. 
Funding: This research was funded by the Italian Ministry of Health ("Ricerca Finalizzata" GR-201102351128).

Institutional Review Board Statement: The study was conducted according to the guidelines of the Declaration of Helsinki and approved by the Institutional Review Board of the University of Padova and the Italian Ministry of Health (protocol code 938/2016-PR, obtained on 4 August 2016).

Informed Consent Statement: Not applicable.

Data Availability Statement: Data are available upon reasonable request to the corresponding authors.

Conflicts of Interest: The authors declare no conflict of interest.

\section{References}

1. Maeda, H.; Wu, J.; Sawa, T.; Matsumura, Y.; Hori, K. Tumor Vascular Permeability and the EPR Effect in Macromolecular Therapeutics: A Review. J. Control. Release 2000, 65, 271-284. [CrossRef]

2. Pasut, G. Grand Challenges in Nano-Based Drug Delivery. Front. Med. Technol. 2019, 1, 1. [CrossRef]

3. Wu, A.M.; Senter, P.D. Arming Antibodies: Prospects and Challenges for Immunoconjugates. Nat. Biotechnol. 2005, 23, 1137-1146. [CrossRef] [PubMed]

4. Tolcher, A.W. Antibody Drug Conjugates: Lessons from 20 Years of Clinical Experience. Ann. Oncol. 2016, 27, 2168-2172. [CrossRef]

5. Grigoletto, A.; Maso, K.; Mero, A.; Rosato, A.; Schiavon, O.; Pasut, G. Drug and Protein Delivery by Polymer Conjugation. J. Drug. Deliv. Sci. Technol. 2016, 32, 132-141. [CrossRef]

6. Canal, F.; Vicent, M.J.; Pasut, G.; Schiavon, O. Relevance of Folic Acid/Polymer Ratio in Targeted PEG-Epirubicin Conjugates. J. Control. Release 2010, 146, 388-399. [CrossRef]

7. Pasut, G.; Canal, F.; Dalla Via, L.; Arpicco, S.; Veronese, F.M.; Schiavon, O. Antitumoral Activity of PEG-Gemcitabine Prodrugs Targeted by Folic Acid. J. Control. Release 2008, 127, 239-248. [CrossRef]

8. Clementi, C.; Miller, K.; Mero, A.; Satchi-Fainaro, R.; Pasut, G. Dendritic Poly(Ethylene Glycol) Bearing Paclitaxel and Alendronate for Targeting Bone Neoplasms. Mol. Pharm. 2011, 8, 1063-1072. [CrossRef] [PubMed]

9. Miller, K.; Clementi, C.; Polyak, D.; Eldar-Boock, A.; Benayoun, L.; Barshack, I.; Shaked, Y.; Pasut, G.; Satchi-Fainaro, R. Poly(Ethylene Glycol)-Paclitaxel-Alendronate Self-Assembled Micelles for the Targeted Treatment of Breast Cancer Bone Metastases. Biomaterials 2013, 34, 3795-3806. [CrossRef] [PubMed]

10. Wang, S.; Low, P.S. Folate-Mediated Targeting of Antineoplastic Drugs, Imaging Agents, and Nucleic Acids to Cancer Cells. J. Control. Release Off. J. Control. Release Soc. 1998, 53, 39-48. [CrossRef]

11. Sudimack, J.; Lee, R.J. Targeted Drug Delivery via the Folate Receptor. Adv. Drug. Deliv. Rev. 2000, 41, 147-162. [CrossRef]

12. Rijnboutt, S.; Jansen, G.; Posthuma, G.; Hynes, J.B.; Schornagel, J.H.; Strous, G.J. Endocytosis of GPI-Linked Membrane Folate Receptor-Alpha. J. Cell. Biol. 1996, 132, 35-47. [CrossRef]

13. Liang, X.; Luo, M.; Wei, X.-W.; Ma, C.-C.; Yang, Y.-H.; Shao, B.; Liu, Y.-T.; Liu, T.; Ren, J.; Liu, L.; et al. A Folate Receptor-Targeted Lipoplex Delivering Interleukin-15 Gene for Colon Cancer Immunotherapy. Oncotarget 2016, 7, 52207-52217. [CrossRef]

14. Tiernan, J.P.; Perry, S.L.; Verghese, E.T.; West, N.P.; Yeluri, S.; Jayne, D.G.; Hughes, T.A. Carcinoembryonic Antigen Is the Preferred Biomarker for in Vivo Colorectal Cancer Targeting. Br. J. Cancer 2013, 108, 662-667. [CrossRef] [PubMed]

15. Chen, Y.-L.; Chang, M.-C.; Huang, C.-Y.; Chiang, Y.-C.; Lin, H.-W.; Chen, C.-A.; Hsieh, C.-Y.; Cheng, W.-F. Serous Ovarian Carcinoma Patients with High Alpha-Folate Receptor Had Reducing Survival and Cytotoxic Chemo-Response. Mol. Oncol. 2012, 6, 360-369. [CrossRef]

16. D'Angelica, M.; Ammori, J.; Gonen, M.; Klimstra, D.S.; Low, P.S.; Murphy, L.; Weiser, M.R.; Paty, P.B.; Fong, Y.; DeMatteo, R.P.; et al. Folate Receptor- $\alpha$ Expression in Resectable Hepatic Colorectal Cancer Metastases: Patterns and Significance. Mod. Pathol. 2011, 24, 1221-1228. [CrossRef]

17. Pasut, G.; Greco, F.; Mero, A.; Mendichi, R.; Fante, C.; Green, R.J.; Veronese, F.M. Polymer-Drug Conjugates for Combination Anticancer Therapy: Investigating the Mechanism of Action. J. Med. Chem. 2009, 52, 6499-6502. [CrossRef]

18. Santucci, L.; Mencarelli, A.; Renga, B.; Pasut, G.; Veronese, F.; Zacheo, A.; Germani, A.; Fiorucci, S. Nitric Oxide Modulates Proapoptotic and Antiapoptotic Properties of Chemotherapy Agents: The Case of NO-Pegylated Epirubicin. FASEB J. 2006, 20, 765-767. [CrossRef]

19. Frión-Herrera, Y.; Gabbia, D.; Scaffidi, M.; Zagni, L.; Cuesta-Rubio, O.; De Martin, S.; Carrara, M. The Cuban Propolis Component Nemorosone Inhibits Proliferation and Metastatic Properties of Human Colorectal Cancer Cells. Int. J. Mol. Sci. 2020, $21,1827$. [CrossRef] [PubMed]

20. Frión-Herrera, Y.; Gabbia, D.; Cuesta-Rubio, O.; De Martin, S.; Carrara, M. Nemorosone Inhibits the Proliferation and Migration of Hepatocellular Carcinoma Cells. Life Sci. 2019, 235, 116817. [CrossRef] [PubMed]

21. Gabbia, D.; Pozzo, L.; Zigiotto, G.; Roverso, M.; Sacchi, D.; Dalla Pozza, A.; Carrara, M.; Bogialli, S.; Floreani, A.; Guido, M.; et al. Dexamethasone Counteracts Hepatic Inflammation and Oxidative Stress in Cholestatic Rats via CAR Activation. PLoS ONE 2018, 13, e0204336. [CrossRef] [PubMed] 
22. Gabbia, D.; Roverso, M.; Guido, M.; Sacchi, D.; Scaffidi, M.; Carrara, M.; Orso, G.; Russo, F.P.; Floreani, A.; Bogialli, S.; et al. Western Diet-Induced Metabolic Alterations Affect Circulating Markers of Liver Function before the Development of Steatosis. Nutrients 2019, 11, 1602. [CrossRef]

23. Orlando, R.; De Martin, S.; Andrighetto, L.; Floreani, M.; Palatini, P. Fluvoxamine Pharmacokinetics in Healthy Elderly Subjects and Elderly Patients with Chronic Heart Failure. Br. J. Clin. Pharmacol. 2010, 69, 279-286. [CrossRef] [PubMed]

24. Malki, A.; ElRuz, R.A.; Gupta, I.; Allouch, A.; Vranic, S.; Al Moustafa, A.-E. Molecular Mechanisms of Colon Cancer Progression and Metastasis: Recent Insights and Advancements. Int. J. Mol. Sci. 2020, 22, 130. [CrossRef] [PubMed]

25. Bhattacharya, R.; Fan, F.; Wang, R.; Ye, X.; Xia, L.; Boulbes, D.; Ellis, L.M. Intracrine VEGF Signalling Mediates Colorectal Cancer Cell Migration and Invasion. Br. J. Cancer 2017, 117, 848-855. [CrossRef] [PubMed]

26. Said, A.; Raufman, J.-P.; Xie, G. The Role of Matrix Metalloproteinases in Colorectal Cancer. Cancers 2014, 6, 366-375. [CrossRef] [PubMed]

27. Yamada, T.; Das Gupta, T.K.; Beattie, C.W. P28-Mediated Activation of P53 in $\mathrm{G}_{2}-\mathrm{M}$ Phase of the Cell Cycle Enhances the Efficacy of DNA Damaging and Antimitotic Chemotherapy. Cancer Res. 2016, 76, 2354-2365. [CrossRef]

28. Demidenko, Z.N.; Kalurupalle, S.; Hanko, C.; Lim, C.; Broude, E.; Blagosklonny, M.V. Mechanism of G1-like Arrest by Low Concentrations of Paclitaxel: Next Cell Cycle P53-Dependent Arrest with Sub G1 DNA Content Mediated by Prolonged Mitosis. Oncogene 2008, 27, 4402-4410. [CrossRef]

29. Song, G.; Xu, S.; Zhang, H.; Wang, Y.; Xiao, C.; Jiang, T.; Wu, L.; Zhang, T.; Sun, X.; Zhong, L.; et al. TIMP1 Is a Prognostic Marker for the Progression and Metastasis of Colon Cancer through FAK-PI3K/AKT and MAPK Pathway. J. Exp. Clin. Cancer Res. 2016, 35, 148. [CrossRef]

30. Kryczka, J.; Stasiak, M.; Dziki, L.; Mik, M.; Dziki, A.; Cierniewski, C.S. Matrix Metalloproteinase-2 Cleavage of the B1 Integrin Ectodomain Facilitates Colon Cancer Cell Motility. J. Biol. Chem. 2012, 287, 36556-36566. [CrossRef]

31. Zhang, M.; Liu, Y.; Feng, H.; Bian, X.; Zhao, W.; Yang, Z.; Gu, B.; Li, Z.; Liu, Y. CD133 Affects the Invasive Ability of HCT116 Cells by Regulating TIMP-2. Am. J. Pathol. 2013, 182, 565-576. [CrossRef] [PubMed] 